AUS $\mid \begin{aligned} & \text { American University } \\ & \text { of Sharjah }\end{aligned}$

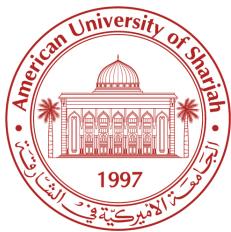

SCHOOL OF BUSINESS ADMINISTRATION WORKING PAPER SERIES

SBAWPS: 03-04/2015

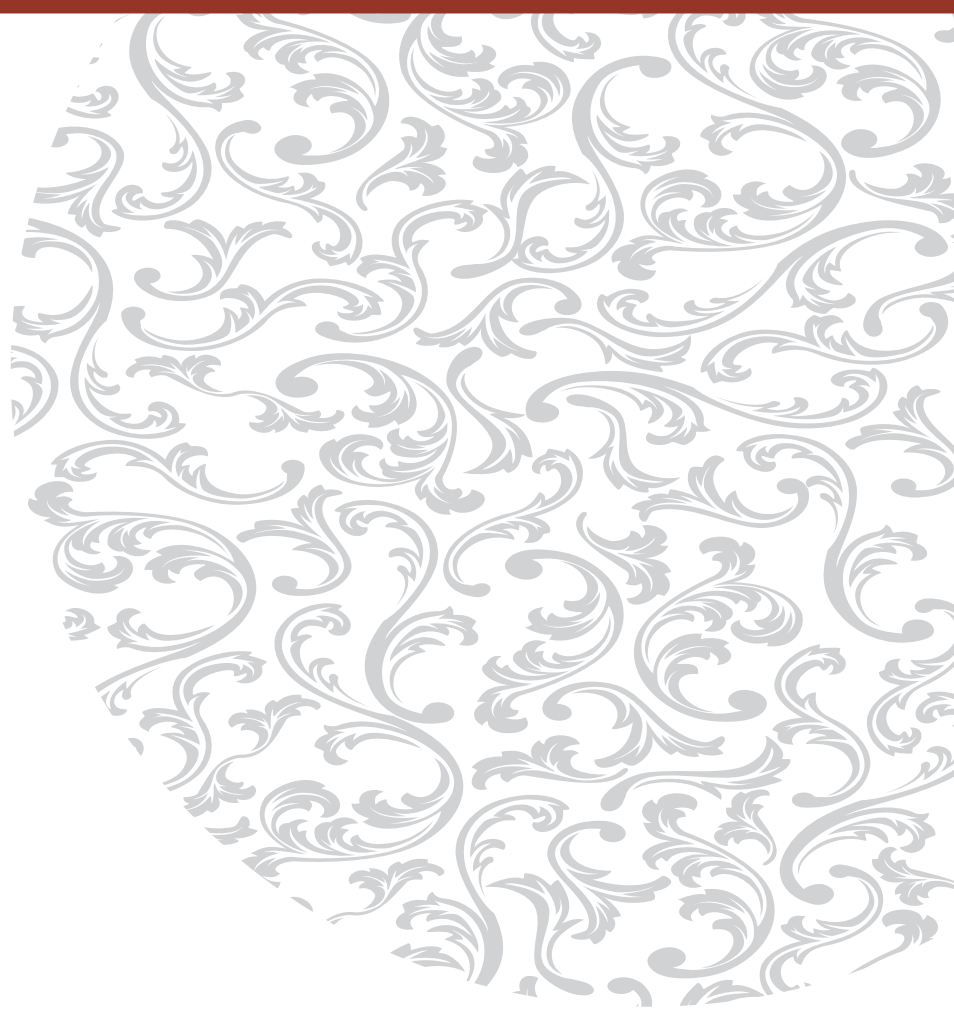

Governance and Short Sales

Daniel Dupuis

Lawrence Kryzanowski 
Working Paper 03-04/2015

School of Business Administration

Working Paper Series (SBA WPS)

\section{Governance and Short Sales}

\section{Daniel Dupuis}

American University of Sharjah

\section{Lawrence Kryzanowski}

Concordia University

The views expressed in papers published in our series are those of the author(s) and do not necessarily represent those of any department at SBA, the SBA itself, the American University of Sharjah (AUS) and/or any of their affiliates. Additionally, all papers in the series are made available on an "as is" basis without warranties of any kind. We, that is, the relevant department at SBA, SBA, AUS and/or any of the affiliates, hereby expressly disclaim any warranties of any kind, whether expressed or implied, including without limitation, the warranties of noninfringement, merchantability, and fitness for a particular purpose. Furthermore, we offer no warranties, expressed or implied, regarding the accuracy, sufficiency or suitability of the material found in the published papers. The users have the sole responsibility for inspecting and testing all content to their satisfaction before using them. 


\title{
Governance and Short Sales
}

\author{
Daniel Dupuis \\ Assistant-Professor, Department of Finance \\ School of Business Administration \\ American University of Sharjah \\ Sharjah, United Arab Emirates, P.O. Box 26666. E-mail: ddupuis@aus.edu
}

\section{Lawrence Kryzanowski}

Senior Concordia University Research Chair in Finance, Department of Finance John Molson School of Business

Concordia University

Montreal, P.Q., Canada, H3G 1M8. Telephone: + 1 514-848-2424, ext. 2782.

E-mail: lawrence.kryzanowski@concordia.ca. 


\title{
Governance and Short Sales
}

\begin{abstract}
This paper investigates the relationship between short sales and governance. We argue that short sales are reversely linked to the overall level of corporate governance of a firm and that sellers react contemporaneously to changes in such governance. Our results show that short traders may also be able to forecast or influence changes in corporate governance and adjust their portfolios accordingly prior to the said changes. This reaction is asymmetric, with a pronounced increase in short positions for actual and anticipated negative changes in governance and a more subdued repurchase of shorted stock for positive expectations. We provide empirical evidence consistent with the notion that short sellers are informed investors and can generate a profit from corporate events by using analytical prowess or manipulative practices such as the record-date capture technique.
\end{abstract}

Keywords: Short sales; corporate governance.

JEL Classifications: D53, G11, G14, G30, G34. 


\section{Governance and Short Sales}

\section{INTRODUCTION}

Short sales have been the subject of many debates in the academic literature and the finance industry. The bulk of the debate revolves around the potential impact of short sellers on market efficiency and the resulting requirement for a regulatory framework (or lack thereof). The general opinion of researchers is that unrestricted short sales are actually beneficial to the market (Charoenrook and Daouk, 2005; Beber and Pagano, forthcoming; Boehmer et al., 2013; Boulton and Braga-Alves, 2010). By rapidly integrating new information into stock valuation, price accuracy and liquidity naturally increase. In an effort to generate profits, short sellers also engage in research activities, revealing new information that may have been previously overlooked, thereby improving market transparency and efficiency. Opponents to this point of view include politicians and corporate CEOs who claim that short sales can be used to manipulate share prices but there appears to be little support for this argument in the current literature.

Research on the topic of short selling also focuses on the profits generated by this activity. While the consensus is that short sellers generate healthy abnormal returns, the methods or strategies used to achieve these higher yields are still relatively under researched. Superior analytical capabilities attributed to higher sophistication appear to be the norm among short sellers who can sometimes pre-empt price downturns due to changes in fundamentals or other firmspecific events. The literature mentions ownership concentration, lower fundamental ratios, negative news, financial misconduct and earnings restatements as some of the drivers of short 
sales. These are all items directly or indirectly related to corporate governance or lack thereof. If a company is well managed, there should be less incentive to short its stock.

This study links corporate control and market finance to form a bridge between two distinct branches of the existing literature: governance and short sales. It contributes to the literature by providing a new insight into the decision-making process of short sellers, using an extensive and comprehensive dataset that spans an entire market cycle. We accomplish this task by investigating the contemporaneous and temporal impact of governance ratings on the level of short sales. We also examine the determinants of short sales as previously established in the literature.

We find that there is a significant relationship between the utilization, a relative measure of the level of short sales defined as the ratio of borrowed shares over total lendable stock, and the CGQ (Corporate Governance Quotient) ratings of the same period, indicating that sellers adopt a short position commensurate with the current governance practices of a firm. Lower ratings are associated with a higher level of short sales. Furthermore, short sellers adjust their stance when there is a material change in the level of governance of the targeted firm, implying an active change in trading strategy as opposed to a simple monotonous short position. Utilization, or relative short interest, increases when governance weakens, and short sales decrease with a more subdued effect when the CGQ rating of a firm increases.

Lagged utilization is particularly informative when studying short interest. There is a high correlation for short sales from month to month but this pattern is broken when a governance event occurs. Our results show that the utilization level increases in the period prior to a change in CGQ ratings, indicating that they may be able to forecast such events and react accordingly. These findings shed light on the motivations of sellers and are consistent with the notion that short traders are informed investors. Alternatively, our results can be viewed as evidence of the use of a legal 
but manipulative technique called record-date capture where the seller decouples economic and voting ownership over the record date (prior to the corporate event), sells the stock then uses his voting right at the shareholder's meeting to decrease firm value before repurchasing the shares at a lower price.

We also find that many of the determinants of relative short interest previously identified become insignificant when coupled with CGQ ratings. This is the case for fundamental ratios, market capitalization and the presence of options for a specific stock. Lagged utilization, shorting fee and institutional ownership remain as significant independent variables.

The remainder of this paper is organized as follows. Section two consists of a literature review. Section three describes our sample and data. Section four discusses our hypotheses and the determinants of utilization. Section five presents our empirical methodology and results. Section six details our robustness tests. Section seven concludes the paper.

\section{LITERATURE REVIEW}

A short sale is essentially the result of an investor selling an asset he does not own with the objective of repurchasing it at a later date and at a lower price to cover the short position. The process is completed when the seller borrows the asset in question from various market participants and delivers it to the buyer in exchange for payment. While the stock is under loan, the ownership of the security is transferred to the borrower along with all of the rights/responsibilities this ownership carries (dividends, voting rights, etc.). The act of borrowing, referred to as "securities lending”, is subject to fees and costs and presents many potential dangers. The proceeds of the sale are not available to the seller since it is escrowed as collateral. The Federal Reserve requires that 
a further $50 \%$ of the dollar-equivalent of the trade be added to the collateral in question. Furthermore, short sellers are subject to the threat of a "short squeeze" when the initial lender of the securities calls its loan with the intention of selling the shares on the open market, forcing the borrower to liquidate its position when no other lenders are available (Dechow et al., 2001). For these reasons, short sellers are believed to be mostly institutional investors.

Christophe et al. (2004) uncover a significant negative relationship between pre-earnings short sales and post-announcement prices. They conclude that “... a significant portion of the short sellers are informed traders” (p. 1846). ${ }^{1}$ Boehmer et al. (2008) estimate that approximately 98\% of all short sales originate from institutions, proprietary traders and specialists while the remaining $2 \%$ is attributed to individuals. They show that short sellers, as a group, are "extremely well informed" (p. 524) and that "short sellers possess important information and that their trades are important contributors to more efficient stock prices.” (p. 525). This conjecture is supported by the fact that short selling is considered risky and costly compared with long positions (Dechow et al, 2001).

With few exceptions, there is ample evidence in the academic literature that short sellers generate abnormal positive returns (Senchack and Starks, 1993; Asquith and Meulbroek, 1996; Aitken et al., 1998; Dechow et al., 2001). Desai et al. (2002) also state that "heavily shorted firms experience negative abnormal returns of -0.76 to $-1.13 \%$ monthly”, or approximately $12 \%$ yearly. These findings are supported by Diether et al. (2008) who determine that "a trading strategy that buys stocks with low short-selling activity and sells short stocks with high short-selling activity generates an abnormal return of roughly 1.39\% (1.41\%) per month for the NYSE (Nasdaq)”.

\footnotetext{
${ }^{1}$ Christophe et al. (2004) further contend that pre-announcement trades, although partially explained by firm attributes, are more likely driven by specific information about the upcoming announcement.
} 
Woolridge and Dickinson (1994) provide a dissenting opinion but their paper fails to differentiate between speculation-driven and arbitrage/hedging motivated short sales, thereby generating skewed results. The magnitude of short-interest positions (\% shorted divided by outstanding shares) plays a determinant role in sorting the purpose of the short position. Focusing on stocks with a short interest of $2.5 \%$ of shares outstanding or more provides better information on speculative forces and avoids the trap of including arbitrage and hedging transactions (Dechow et al., 2001; Aitken et al., 1998).

Once it is established that short sellers do generate abnormal returns, the following question naturally comes to mind: “How do they do it?” Granted, they are mostly informed institutional investors with sizable resources at their disposal but market efficiencies should eliminate the possibility of abnormal returns. While it is a well-known fact that market frictions combined with behavioural factors may cause prices to temporarily deviate from fundamental value (Miller, 1977; Scheinkman and Xiong, 2003; DeBondt and Thaler, 1985; Daniel et al., 1998, Hong and Stein, 1999), does it mean that short sellers as a group are uncharacteristically astute and can take advantage of these imperfections? A number of papers have attempted to investigate the methods and strategies used by short sellers to answer this question.

As a group, short sellers actively target firms with low fundamental to market ratios. Dechow et al. (2001) determine that when market prices are high, short interest is also high for stocks with lower than normal cash flow/price, earnings/price and book/market ratios. A possible justification for this phenomenon is that short sellers simply recognize that stocks are overvalued and act accordingly. Francis et al. (2005) agree with this conclusion but differ on the reasons. Their work shows that the increase in short interest is due to overestimated fundamentals and underestimated risk factors, leading to mistakenly high expected returns. In both cases, short sellers act as a 
dampening force to realign stock prices. This is partially supported by Diether et al. (2008) who determine that short sales increase after a stock has shown a string of strong returns.

Announcements and news also have a marked impact on short sales; newly disclosed negative public information is normally followed by an increase in short interest (Christophe et al., 2004; Desai et al., 2006, Engelberg et al., 2012). Fox et al. (2009) explain that short sellers can actually predict negative news and pre-empt the market by short selling ahead of the news releases, earning abnormal returns in the process. In the same vein, Karpoff and Lou (2010) study the effect of financial misrepresentation on short sales and conclude that short sellers' actions realign the stock prices with the correct fundamental value prior to the disclosure of misconduct, thereby providing uninformed investors with valuable external benefits. The relationship between management quality and short sales is further detailed by Drobetz et al. (2004) who conclude that investors will use the "Wall Street Walk" when faced with poor executive decisions. They will sell shares instead of trying to influence management. Ownership dispersion also has an intuitive link to short interest. With a high concentration of stock in the hands of institutional owners, shares are easier and cheaper to borrow, thereby encouraging short sales. Desai et al. (2006) study the behaviour of short sellers around earnings restatements and find that they begin accumulating short positions several months before the restatement, thereby generating favourable returns from the detection of suspicious financial reporting.

Thus, there is a clear and demonstrated relationship between short sales, company fundamentals, announcements, ownership structures, financial misrepresentations and restatements. These are all variables that can be considered as proxies for corporate governance.

\section{SAMPLE AND DATA}




\subsection{Governance Data}

The data sample has been chosen to cover a full market cycle from July 2006 to July 2009, including the bull market ending in 2007 and the subsequent crash and recovery. The quality level of governance is approximated by RiskMetrics’ Corporate Governance Quotient (CGQ $\left.{ }^{\circledR}\right)$. The CGQ rating is built by evaluating each company against 67 criteria covering the full range of corporate governance (board, audit, charter/bylaws, takeover practices, compensation, ownership and other qualitative factors). Any material changes in the level of governance are recorded at the time they are instigated, usually as a result of the vote held during a shareholder's meeting. The firm rating is updated accordingly on that same date. The raw score obtained is then compared with other firms from the same index and a ranking system ensues where the CGQ index score is the company's relative percentile ranking among its peers. For example, an Index CGQ of 84 indicates that the company's raw score was higher than $84 \%$ of the other firms in the same index. Simply put, a high CGQ ranking indicates better corporate governance practices. The CGQ database features over 5400 US companies with monthly scores. Since governance ratings do not change on a daily basis (or even monthly in most cases), this frequency level is satisfactory for the purpose of our study. Changes in governance ratings may have various causes. Examples that have an impact on the CGQ rating include the nomination of the CEO on the board to auditor rotation, features of poison pills, director compensation, board performance review, and stock ownership guidelines for executives.

Of the 5400 firms covered by the dataset, 3962 have continuous governance history for the 37 months included in our sample. Ratings range from 0.1 to 100 , with a mean of 52.95, median of 54.40, standard deviation of 28.42 and skewness of -0.09 . Kurtosis is relatively low at 1.83 . Table 1 provides the descriptive statistics for the CGQ ratings. 


\section{[Please insert table 1 about here.]}

\subsection{Short-sales Data}

The level of utilization is used as a proxy for short sales. Utilization is the number of securities on loan divided by the total number of lendable shares. It provides a more accurate estimate of short sales than pure short interest and avoids the trap of size, where larger firms would show higher raw short sales because of their market capitalization. Utilization is a close proxy for short interest but it is not perfect. Tax arbitrage - the act of lending securities to a domestic entity to avoid withholding tax in the hands of an international investor - has a limited impact on the quality level of utilization as a proxy for short interest. Prior to the Tax Relief Act of 1997, this technique was also widely used by U.S. entities for domestic holdings but the practice has since disappeared along with the tax advantages. Dividend reinvestment arbitrage provides a similar dilemma since investors sometimes exchange the dividend payment for a lending fee. Nevertheless, the benefits of using securities lending as a proxy (frequency, availability of data, etc.) far outweigh its shortcomings. Firm size can have an impact on the level of short sales. Short sellers are believed to be skilful investors and stocks with large capitalizations tend to be followed more closely by analysts and institutional investors. Furthermore, the pool of lendable securities increases with firm size, which lowers the cost and difficulty of borrowing shares. All other things being equal, larger firms will have more lendable stock and selecting utilization as a proxy for short sales reduces the need to control for firm size.

Direct monthly short sale data are available from various market reports. Unfortunately, many short positions are closed within a few days and a monthly "snapshot" will not provide adequate information so alternative sources are necessary. The trend in short-sales research is to use securities lending data as a proxy for relative short interest. Several studies employ security loan 
rate data to measure the effect of short-sales constraints (e.g., Reed, 2001; Jones and Lamont, 2002; D’Avolio, 2002; Saffi and Sigurdson, 2011). For this paper, securities lending data from Data Explorer's Securities Finance Data Feed is used as a proxy for short sales. It is one of the most comprehensive datasets available on the market containing daily granular data for over 30,000 equities worldwide with stock-level loan data from over 100 market participants. For the period covered by this study, this amounts to over seven million data points. To limit the field and match the governance figures, we have restricted the dataset to cover only US equities for the period of July 2006 to July 2009. This daily dataset is collected from hundreds of securities lenders and covers approximately $80 \%$ of all worldwide OTC and organized exchange transactions, with higher coverage for North American markets. It provides details such as the borrowed and lendable quantities and values, lending fees, loan tenure, and utilization.

To match our CGQ sample, we restrict the array of stocks to the 3962 firms under study. Each stock has one or more daily observations for aggregate short-sales transactions per lender for a period of 37 months; a total of 4,397,820 observations or 146,594 monthly averages. Further investigation reveals that all but one of the firms with no short sales over the entire sample period are "pink sheets” penny stocks with little or no volume. They are eliminated from the sample as they would not be subject to short sales due to the absence of liquidity.

We take the monthly utilization mean for all stocks to match the frequency of the corporate governance data. Utilization ranges from 0 to $100 \%$, with some stocks showing no short sales at all over the three year period. The mean is $29.83 \%$, with a median of $23.23 \%$, a standard deviation of 22.91\%, skewness of 0.94 and kurtosis close to that of a normal distribution at 3.03. As per Dechow et al. (2001) and Aitken et al. (1998), we eliminate all stock-months where utilization is below $2.5 \%$ to remove arbitrage and hedging transactions. After accounting for changes in the 
CUSIP, delisting and missing data, we obtain a dataset containing 3072 stocks with 113,664 data points detailing monthly governance ratings, securities lending averages and value-weighted average fees. Table 1 provides the descriptive statistics for the final sample.

\section{HYPOTHESES AND POSSIBLE SHORT-INTEREST DETERMINANTS}

\subsection{Hypotheses Development}

"Corporate governance is the system by which companies are directed and controlled" is a simple but far reaching comment taken from the 1992 Cadbury report. In essence, corporate governance mechanisms ensure that fund providers get proper returns on their investments. Methods used to enforce corporate honesty against poor governance include separation of ownership and control, protection of shareholder rights, legal prohibitions against self-dealing and concentrated ownership. Agency theory is considered the point of origin of any discussion on corporate governance. To safeguard their capital and generate an acceptable return, investors must ensure that managements act in the best interests of the fund providers. In developed countries, the principal-agent problem is partially solved by adopting a costly framework composed of legal restrictions, corporate charters and bylaws, as well as the threat of corporate control changeovers. Since the implementation of these defence mechanisms impose a burden on the firm's bottom line, investors require higher compensation for the additional costs they must bear. However, the general consensus among market participants, regulators and researchers is that better governance, which steers time and resources away from monitoring management, reduces the required rate of return, hence lowering the cost of capital.

A better understanding of the relationship between short sales and governance can be obtained from an examination of the dividend-discounting framework where the stock price (and ultimately 
the theoretical value of the firm) is a function of the book value of common equity plus the actualized value of all future abnormal earnings (Edwards and Bell, 1961; Ohlson, 1995). These future abnormal earnings are discounted at $k$, the cost of common equity capital or required rate of return:

$$
P_{j, t}=B_{t}+\sum_{\tau=1}^{\infty} \frac{E_{j, t}\left(x_{t+\tau}^{a}\right)}{\left(1+k_{j}\right)^{\tau}}
$$

Where $P_{j, t}$ is the price estimated or observed by trader (or analyst) $j$ at time $t, B_{t}$ is the book value of common equity at time $t ; E_{j, t}\left(x_{t+\tau}^{a}\right)$ is the investor's estimate at time $t$ of the value of abnormal earnings at time $(t+\tau)$ and $k_{j}$ is the cost of common equity capital. The price $P_{j, t}$ and the required rate of return $k_{j}$ are endogeneous variables. For a given market price, we can extract the implied cost of equity but the model is commonly used to estimate, from the perspective of an analyst $j$, the value of a firm's stock $P_{j, t}$ for a specific desired rate of return $k_{j}$.

The key parameter in this valuation model remains the discount rate $k$. Under-estimating the required rate of return will lead to an overvaluation of the firm's equity while over-estimating it will have the opposite effect. Numerous methods are used to estimate $k$. For example, the CAPM uses the risk-free rate plus a risk premium. All of these techniques demand careful analysis of the target firm. This is an undertaking which requires significant resources, both in the form of human capital and analytical tools. Institutional investors are well equipped for the task and it is expected that they should be more precise than individuals in their estimation of the cost of capital (or future abnormal returns), and will react more rapidly in the event of an unexpected change in the governance structure of a firm that affects the parameters in (1).

While the concept of weak governance appears relatively simple, expressing it in quantifiable terms is somewhat more complicated. In their paper, Gompers, Ishii and Metrick (2003) devise a 
measurable metric for the quality level of corporate governance based on the restriction of shareholder rights. Their findings link strong shareholder rights with higher stock returns. This was later confirmed by Drobetz et al. (2004) who construct a Corporate Governance Rating scale for the German market based on corporate governance commitment, shareholder's rights, transparency, auditing and management board matters. A poor score implies a higher likelihood of financial misrepresentation, more frequent restatements and generally weaker management, driving the cost of capital higher and firm value lower. These studies are the precursor to the creation of the CGQ database we use in our analysis.

As discussed, short sales are mostly the domain of institutional investors and lead to a realignment of stock prices with their fundamental values. Furthermore, unrestricted short sales increase the informational content of markets (Diamond and Verracchia, 1987). Efficient and transparent markets reduce risk, thereby reducing the required rate of return. Charoenrook and Daouk (2009) empirically confirm that the presence of short sales reduces $k$ through liquidity improvement, variance reduction and enhanced risk sharing.

Since the required rate of return is linked to both corporate governance and short sales, we expect to find a significant relationship between the two domains. This insight leads to three distinct testable hypotheses. First, the level of governance, by itself, should provide information about the level of short sales. Second, a (favorable) change in the governance rating of the firm (as a result of a vote at a shareholder meeting for example) should have a contemporary (inverse) effect on short interest. Third, short sellers may be able to anticipate material changes in corporate governance due to board decisions, shareholder activism or any firm-specific event that has an impact on the governance rating. 
We begin by examining the general relationship between governance and short sales. Better governance leads to a lower cost of capital $(k)$, and this lower cost of capital drives expected firm valuation higher, thereby reducing short sales. Therefore, the level of utilization should have a negative relationship with corporate governance. For this test, no causality is implied. Our first hypothesis in its alternative form is as follows:

$H_{a}^{1}$ : The level of corporate governance is negatively related with the level of relative short interest.

Short sellers react to news, earnings announcements, financial misconduct and any corporatedriven events that can have a material impact on valuation. If firm $i$ in month $t$ experiences a material change in its governance rating, it is expected that short sellers will react by immediately reducing or eliminating their short positions for value-creating (positive changes in CGQ ratings) events or increase short sales for expected losses in value (negative changes in CGQ ratings). Thus, our second hypothesis in its alternate form is as follows:

$H_{a}^{2}$ : A negative (positive) change in the governance level of a firm is positively (negatively) related contemporaneously with the change in the level of utilization.

Desai et al. (2006), Karpoff and Lou (2010) and Fox et al. (2009) study the effect of firmspecific events such as earnings restatements, financial misrepresentations and negative corporate news. They conclude that not only do the short sellers react to events as they unfold but that they can actually predict the news by accumulating short positions ahead of the announcements. If short sellers can correctly anticipate changes in governance, this should be incorporated into the level of utilization in the period prior to the event. We formulate our third hypothesis in its alternate form to test whether the same conclusion can be drawn for changes in governance: 
$H_{a}^{3}$ : A negative (positive) change in the governance level of a firm is preceded by a high (low) level of relative short interest.

\subsection{Potential Determinants of Relative Short Interest}

Many firm-specific factors have an effect on utilization and they are the subject of numerous studies. Graham et al. (1999) argue that trading costs have a direct influence on short sales; traders are more likely to short sell a stock when the cost is lower. Many proxies are used to estimate this cost. Higher trading volumes imply better liquidity and a resulting lower cost, and significant institutional ownership reflects a larger pool of lendable securities and also reduces borrowing rates. Since firms with higher market capitalizations tend to show higher levels of institutional ownership (Sias and Starks, 1997), it can be argued that market capitalization is also a proxy for trading costs. Gintschel (2001) finds that market capitalization and turnover explain 58\% of the cross-sectional variation in average short interest. Fortunately, the short-sales database used in this study also contains explicit data on shor- selling fees on an aggregate per-lender level so no proxy for the costs of borrowing shares is necessary.

In our regressions, the independent variable logShortCost accounts for the effect of trading costs on utilization. Because of outliers and the wide range of values (from 0 to 8000 basis points) reported for this variable, we take the log of the monthly value-weighted average fees as the control variable. Options and short sales can both be used to achieve a short position. Therefore, it is expected that the existence of options on a stock should have an effect on the level of relative short interest for that firm. Many studies confirm this assumption. For example, Gintschel (2001), Arnold et al. (2005) and Henry and MacKenzie (2007) conclude that short-interest levels are significantly related to the availability of options for a specific stock. We test the existence of 
options as a regressor and find in untabulated results that it is insignificant when the CGQ rating, lagged utilization and institutional ownership are used as independent variables. ${ }^{2}$

The effect of past short sales on present utilization, also known as short momentum, is well documented in the literature. McKenzie and Henry (2007) and Dechow et al. (2001) report that short momentum is a significant control variable in assessing models related to short sales. Thus, we include a lagged term, Utilization , $_{i, t-1}$, in our regressions.

Lower fundamental ratios are also linked to short sales. As investors notice that the book-tomarket or the earnings-to-price ratios wane, they usually increase their short positions to take advantage of the potential drop in stock value. Firms with poorer governance ratings tend to have weaker fundamentals (Brown and Caylor, 2009; Drobetz et al., 2004). The literature on short sales identifies variables that we drop from the subsequently tabulated regression results because they lose their significance when coupled with governance as regressors. This is the case for the retention ratio, Tobin's Q, market capitalization, the existence of options and fundamental ratios such as $\mathrm{P} / \mathrm{E}, \mathrm{M} / \mathrm{B}$, etc. Ownership dispersion also links governance and short sales. Highly concentrated holdings have an impact on short sales through easier access to securities lending and this characteristic is related to governance as high concentration facilitates the enforcement of shareholder rights. Chung et al. (2010) also report that institutional ownership is a determinant factor when considering CGQ ratings. Aggarwal et al. (2014) show that institutions recall their shares to exercise their voting rights thereby reducing the number of shares on loan and restricting the supply of lendable stock. Since utilization is the ratio of these two quantities, we expect that the level of institutional ownership has an impact on relative short sales and thus include it in the list of independent variables.

\footnotetext{
2 These and any other untabulated findings are available from the authors.
} 


\section{EMPIRICAL METHODOLOGY AND RESULTS}

\subsection{Test of the First Alternative Hypothesis}

Our first alternative hypothesis is that a lower level of governance is associated with a higher contemporaneous level of short sales. Since the use of the least square method relies on the stochastic process being stationary and to avoid the possibility of spurious regression results, we first determine if the dependent variable, Utilization $_{i, t}$, is integrated of order one or zero by performing a unit root test. The results (untabulated) indicate that, with a p-value of 0.000 for the Dicker-Fuller test, ${ }^{3}$ we can reject the null of a unit root process and thus conclude that the series is stationary. We then conduct the Hausman test to choose between random and fixed effects and reject the null in favor of the fixed-effects (FE) model. We also complete an F-test and the results ( $p=0.0000)$ indicate that the pooled OLS method is not appropriate. We thus estimate regression model (1) below using a panel regression with period fixed effects and White diagonal standard errors to account for clustered standard errors. Furthermore, when the lagged dependent variable also appears as an explanatory variable as it is the case for equation (1), strict exogeneity of the regressors may no longer hold. Since our sample displays a large number of observations for a fixed number of periods, the least square estimation method may yield biased results. As a test of robustness, we also estimate equation (1) using a dynamic system GMM panel model with two lags (e.g. refer to Arellano and Bover, 1995).

Based on the determinants of utilization previously discussed, our regression model is as follows:

\footnotetext{
${ }^{3}$ Similar results are obtained using the common (Levin, Lin and Chu) and the individual (Perron) unit root processes.
} 


$$
\begin{gathered}
\text { Utilization }_{i, t}=\beta_{0}+\beta_{1} \text { Gov }_{i, t}+\beta_{2} \text { logShortCost }_{i, t}+\beta_{3} \text { Utilization }_{i, t-1} \\
+\beta_{4} \text { InstOwn }_{i, t}+\varepsilon_{i, t}
\end{gathered}
$$

where:

Utilization $_{i, t}$ is the average ratio of shares borrowed to lendable shares for stock $i$ during month $t$

$G o v R_{i, t}$ is the CGQ rating for stock $i$ for month $t$;

$\operatorname{logShortCost}_{i, t}$ is the log of the value-weighted average shorting fee for stock $i$ for month $t$;

Utilization $_{i, t-1}$ is the dependent variable lagged one month to control for short momentum; and InstOwn $n_{i, t}$ is the percentage of shares owned by institutional investors of stock $i$ for month $t$.

Table 2 reports the results for the tests of $H_{a}^{1}$ for our sample that includes 42,915 observations. Panel A provides the output details for the fixed-effects estimation method while Panel B reports the results obtained from the dynamic system GMM panel model. The table also reports the Bayesadjusted critical t-values for the regressions. This adjusted critical t-value accounts for Lindley’s (1957) and Jeffrey’s (1939) statistical paradox that the standard p-values and t-statistics may lose their meaning with large samples. Leamer (1978) introduces a more rigorous test of statistical significance that uses a critical t-value equal to $\sqrt{(n-k)(\sqrt[n]{n}-1)}$, where $n$ is the number of observations $(42,915)$ and $k$ is the number of parameters.

\section{[Please insert table 2 about here.]}

With a $\mathrm{R}^{2}$ value of 0.85 , an F-statistic of $9633(\mathrm{p}$-value $=0.000)$ and a DW statistic of 2.02, we conclude that the regression model is well specified and that there is no issue with serial correlation in the residuals. All coefficients are statistically significant based on both the standard and the more stringent Bayes-adjusted critical t-values. The coefficient for $G o v R_{i, t}$ is negative, 
confirming our hypothesis of an inverse relationship between the CGQ level and short interest. Higher utilization is associated with lower governance and vice-versa. Aggarwal et al. (2014) demonstrate that institutions recall their shares to exercise their voting rights prior to a governance event, thereby reducing the number of borrowed shares and restricting the supply of lendable stock. It could therefore be argued that our findings are the result of a supply and demand equilibrium unrelated to short selling. Utilization is the number of shares on loan divided by lendable stock and always results in a fraction of less than one. Reducing both the numerator and the denominator by the same amount would actually increase this ratio. Since institutional owners will undoubtedly vote to improve the level of governance, the net impact of recalling the shares would be an increase in both utilization and the CGQ rating. Our findings indicate the opposing effect whereby utilization is inversely related to the level of governance, thus putting to rest the argument that our conclusion is a direct consequence of recalls. Our results confirm prior studies indicating that both the shorting fee $\left(\right.$ ShortCost $\left._{i, t}\right)$ and institutional ownership $\left(\right.$ InstOwn $\left._{i, t}\right)$ are positively related to short sales. As utilization rises, lendable shares are more difficult to find and the cost of borrowing the stock subsequently increases. Furthermore, the estimated coefficient for the lagged term Utilization $_{i, t-1}$ is statistically significant and its addition to the regression increases the $\mathrm{R}^{2}$ value from 0.30 to 0.85 , indicating that prior short sales play a strong role in the determination of contemporaneous relative short interest. To determine the linearity of the relationship between governance and short-sales, we perform a piecewise regression with knots at $G o v R_{i, t}=20 \%, 40 \%$, $50 \%, 60 \%$ and $80 \%$. The results (untabulated) show that the coefficients of the dummy variables assigned to all breakpoints are insignificant at the $90 \%$ level. Furthermore, the explanatory power of the model, as expressed by the coefficient of determination, dies not improve with the addition 
of partitions but remains at the 0.85 level. We therefore conclude that the relationship between governance and short-sales is linear.

The results obtained using the dynamic system GMM panel estimation method are qualitatively similar to that of the FE model. As reported in Panel B of Table 2, all the coefficients are statistically significant to Bayes-adjusted critical t-statistics and the signs of $\beta_{1}, \beta_{2}, \beta_{3}$ and $\beta_{4}$ are an exact match to those obtained from the fixed-effect regressions, thus confirming the validity of our results.

\subsection{Endogeneity}

There is a possible econometric concern with the regression technique described in equation (2). The use of a variant of quantity on the left-hand side and short cost on the right side opens the door to the possibility of an endogeneous relationship between the dependent and independent variables. We use two methods to control for this possibility; the Durbin-Wu-Hausman (DWH) test and a two-stage linear regression with instrumental variables. The main difficulty for both techniques lies in the identification of descriptive variables for $\operatorname{logShortCost}_{i, t}$ that are not related to utilization. The literature on short sales provides some insight; D'Aviolo (2002) identifies the level of institutional ownership as a driver of shorting fees, Dechow et al. (2001) indicate that firm size and liquidity are also determining factors and Jones and Lamont (2002) add dividend yields, the existence on an option market and fundamental ratios to the list.

We thus conduct the DWH test using the level of institutional ownership, the log of market capitalization as a proxy for size, the bid-ask spread for liquidity, a dummy variable equal to 1 if options exist on the stock and 0 otherwise, the actual dividend yield for a specific stock-month as well as the market-to-book, price-earnings ratios and firm beta. The residuals $\left(R E S I D_{i, t}\right)$ resulting 
from the regression of shorting cost on these variables are in turn used as an independent variable in equation (2). With a t-statistic of -1.98 , the coefficient for $R E S I D_{i, t}$ is not statistically significant to the Bayes-adjusted critical value of -3.07 , thus eliminating the endogeneity concern in regression equation $(2$

As a measure of robustness, we repeat the test of the first alternative hypothesis using a twostage least square regression with the exogeneous instruments listed above as instrumental variables. The results (untabulated) indicate that the t-statistic for $\beta_{1}$, the coefficient of $G o v R_{i, t}$, remains significant to Bayes-adjusted standards although its t-statistic has changed from -6.27 to -3.85. The coefficient itself is similar qualitatively and quantitatively (-0.0096 versus -0.0121 using the 2LS IV method), further confirming the absence of an endogeneous regressor in model (2).

\subsection{Test of the Second Alternative Hypothesis}

The premise of our second alternative hypothesis is that a change in the level of a firm's governance rating has an impact on the contemporaneous variation in the level of short utilization for that firm. When short sellers are informed of an event that has a material impact on the quality of corporate direction and control, they will adjust their short position to reflect their expectations for future stock returns as opposed to simply maintaining a high short balance. This hypothesis expands the relationship between governance and short sales established with regression model (2) to encompass direct action on the part of the traders, as opposed to a general relationship between two variables.

During the three-year period under study for our sample of 3072 stocks, there are 34,248 events where the governance rating changed from month $t-1$ to $t$. We resize the sample to account for the 
frequency of the different independent variables. Since institutional ownership is reported quarterly while the rest of the data is monthly, the variable $\Delta I n s t O w n_{i, t}$ displays a value of 0 for two months of every quarter and those observations are therefore discarded. The new sanitized sample shows 12,199 observations. We perform the same unit root tests on $\Delta$ Utilization $_{i, t}$ as described in section 5.1 and find that the series is stationary. As per regression model (2), we test $H_{a}^{2}$ by estimating the following regression model using a panel regression with period fixed effects and White diagonal standard errors to account for clustering and, for robustness purposes, with the dynamic system GMM panel method:

$$
\begin{gathered}
\text { SUtilization }_{i, t}=\beta_{0}+\beta_{1} \Delta \text { Gov }_{i, t}+\beta_{2} \Delta \text { logShortCost }_{i, t}+\beta_{3} \text { SUtilization }_{i, t-1} \\
+\beta_{4} \Delta \text { InstOwn }_{i, t}+\varepsilon_{i, t}
\end{gathered}
$$

where all the variables are monthly changes from month $t-1$ to $t$ with the exception of $\Delta$ tilization $_{i, t-1}$, which is from month $t-2$ to $t-1$. The variables are as previously defined for regression model (2).

Based on the results reported in Panel A of Table 3, the adjusted coefficient of determination for the least squares regression (3) is 0.08 and the Durbin-Watson statistic is 1.88 , implying no autocorrelation. The F-statistic for the regression model of 65 is significant (p-value $=0.0000$ ). As expected, the coefficient $\beta_{1}$ is negative and significant ( $\mathrm{p}$-value $\left.=0.0000\right)$, indicating that short sellers increase (decrease) their position for a negative (positive) change in CGQ rating. As per regression model (2), the change in the borrowing cost is significant (p-value $=0.0000$ ) and positively linked to the change in utilization.

\section{[Please insert table 3 about here.]}

Panel B of Table 3 reports the results of regression model (3) estimated using the system GMM procedure for dynamic panels. The outcome is qualitatively similar to that of the fixed-effects 
method with the exception of the coefficient for the change in lending fee, which is now negative but insignificant according to Bayes-adjusted critical t-statistics. The coefficient for the change in governance rating is negative and, with a large t-statistic of -25.77 , further confirms our previous findings.

The variation in lagged utilization $\left(\Delta\right.$ Utilization $\left._{i, t-1}\right)$ is particularly informative. The significantly negative sign of the coefficient ( $p$-value $=0.0000)$ for both the FE and dynamic system GMM methods defines a change in the pattern of short sellers' actions between periods t2 and $t-1$. Because of short momentum, lagged short sales are normally highly correlated with present utilization. The correlation coefficient between Utilization $_{i, t}$ and Utilization $_{i, t-1}$ is 0.9134. Under monotonous conditions (without an intervening event such as a change in governance), we would expect that the coefficient for the change in lagged utilization $\left(\Delta\right.$ Utilization $\left._{i, t-1}\right)$ would be significant and positive as the level of short sales in one period is highly correlated to that of the next. But the expected change in CGQ rating forces the sellers to alter their investing pattern from month $t-2$ to month $t-1$. As a result, in the presence of an anticipated change in governance, the coefficient for the change in lagged utilization should become negative or insignificant. To verify this possibility, we run the same regression on a reduced sample of 1,117 events where the change in CGQ rating is null (0.00). With a coefficient $\beta_{3}$ of -0.004 and a t-statistic of -0.17 , a $\mathrm{R}^{2}$ of 0.06 and $\mathrm{DW}=2.13$ as reported in Panel A of Table 4, the results using the FE method show that the coefficient for $\Delta$ Utilization $_{i, t-1}$ is not statistically different from zero when $\Delta G o v R_{i, t}=0$, indicating that there is no significant change in lagged utilization when there is no change in governance. As detailed in Panel B of Table 4, the dynamic system GMM panel model yields similar results, namely that the coefficient for the lagged change 
in utilization is not significant, confirming our hypothesis that short sellers do not change their position from $t-2$ to $t-1$ when no change in governance is expected.

\section{[Please insert table 4 about here.]}

Thus we conclude that the change in governance forces short sellers to revise their investment strategy, disrupting the previously monotonous pattern and effectively impacting utilization. It is interesting to note that this change in the shorting trend occurs prior to the change in governance, opening the door to the possibility that some of the short sellers can actually forecast the changes in CGQ rating ahead of the rest of the market.

\subsection{Test of the Third Alternative Hypothesis}

Our third alternative hypothesis deals with whether short sellers can actually anticipate changes in governance and hold a short position accordingly in the period prior to the change. In essence, we examine if the level of utilization of month $t-1$ is related to the change in the CGQ rating in period $t$. It could be argued that the change in governance for this test could be the dependent

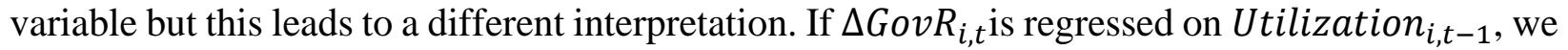
imply causality that short sellers actually influence changes in governance. At this point, we simply want to assess if relative short interest in month $t-1$ is related to the change in CGQ rating from month $t-1$ to $t$. The term Utilization Ut $_{i-2}$ accounts for the impact of short sales in the month prior to the period under study. As per our previous regressions, we use a panel regression with period fixed effects and White diagonal standard errors to account for clustering. We also perform a robustness test with a two-lag dynamic system GMM panel process. The regression model used to test this hypothesis based on our sample of 38,776 change events is as follows:

$$
\begin{gathered}
\text { Utilization }_{i, t-1}=\beta_{0}+\beta_{1} \Delta \text { Gov }_{i, t}+\beta_{2} \text { logShortCost }_{i, t-1}+\beta_{3} \text { Utilization }_{i, t-2} \\
+\beta_{4} \text { InstOwn }_{i, t-1}+\varepsilon_{i, t}
\end{gathered}
$$


where all the terms are as previously defined.

Based on the summary results for the regression model (4) reported in panel A of Table 5, we observe an $\mathrm{R}^{2}$ of 0.84 with an F-statistic of 52,608 (probability 0.000 ). The estimate of least squares coefficient $\beta_{1}$ of -0.0080 is weakly significant (t-statistic $=-1.89$; $\mathrm{p}$-value $=0.0588$ ) and does not meet the more stringent standard of the Bayesian-adjusted critical $t$-value $(t= \pm 3.25)$. We address this issue further in the robustness section of this paper. Alternatively, as described in Panel B of Table 5, the dynamic panel method generates coefficient estimates that are significant to Bayes-adjusted critical t-values for all four independent variables, including $\Delta G o v R_{i, t}$ with a t-statistic of -3.46. With the exception of this stronger relationship between governance and short sales, the results for both regression methods are qualitatively similar. The main purpose of regression (4) is to verify the sign of this coefficient for the change in CGQ ranking. It is negative, indicating that lagged utilization has an inverse relationship with the variation in governance rating. We conclude that, for a specific stock, sellers take a short position in the period preceding a negative change in governance regime or, alternatively, opt for neutral or reduced short holdings for positive changes.

\section{[Please insert table 5 about here.]}

It can thus be inferred that short traders act as informed investors and, using exceptional analytical skills, correctly anticipate the results of the corporate event. There is a possible, although somewhat nefarious, alternative explanation. Our results can be viewed in a different light; it could be argued that short sellers manipulate the governance process to sway decisions in their favor. Using a relatively simple technique called record-date capture, they can legally influence the vote at a shareholder's meeting, depress the stock price and generate profits. Brav and Mathews (2011) present a theoretical model of corporate voting outcomes and conclude that traders who practice 
empty voting (without economic exposure) sometimes sell to a net negative position then exercise their rights and decrease firm value.

The process is as follows. Prior to the record date, the trader takes an economically-neutral position in the firm's stock by using one of many techniques such as simply borrowing the shares, buying the stock and hedging the net exposure with derivatives or entering into an equity swap. By holding this position over the record date, he thus successfully decouples voting and economic ownership. Depending on the state, U.S. law requires that the time lapse between the record date and the shareholder's meeting be at least 11 days. Christoffersen et al. (2007) find a median lag of 54 calendar days between those two events, leaving ample time for the trader to short-sell the borrowed shares after the record date but prior to the investor's gathering. At that meeting, he then strategically votes his position in a way designed to minimize firm value, thereby depressing the stock price and reaping the benefits.

In 2012, the U.S. courts were asked to rule on the legality of this technique in a landmark case pitting Mason Capital Management LLC, an American hedge fund, and Telus Inc., a Canadian telecommunications provider. Mason used the record-date capture method to accumulate close to $20 \%$ of the voting rights with almost no economic exposure, then threatened to exercise these rights to defeat a proposed share consolidation plan. Telus had no choice but to abandon the proposal and chose to pursue Mason in a US court of law. The case was won by Mason in an appeal, thereby opening the door to legal empty voting and the legitimization of the record-date capture practice. Ringe (2013) offers a detailed outline of the legal implications of the case while $\mathrm{Hu}$ and Black (2006) provide an overview of this and other dubious techniques. They also document domestic and international instances where the method has been used to extort a profit. Our results thus support the notion that short traders, by either displaying analytical prowess or 
manipulating the voting system, can predict or influence the outcome of corporate events and adopt a strategically profitable position accordingly.

\subsection{Causality}

While it is established that short positions are positively related to an anticipated negative governance event (and vice-versa), causality still remains in doubt. To study this issue, we reverse the order of our regression and impose $\Delta G o v R_{i, t}$ as the dependent variable and Utilization $_{i, t-1}$ as the independent variable. Following in the footsteps of Moore and Porter (2007), we regress the change in governance from equation (4) on lagged utilization, Tobin’s Q ratio, total firm assets, beta, financial leverage and payout rate. The untabulated results show that the coefficient for Utilization $_{i, t-1}$ is -0.0022 with an insignificant t-statistic of -1.37 . This provides an insight as to the direction of causality; namely, that the expectation of a negative change in the level of governance increases short sales in the period preceding the trigger event. Short sellers thus accurately forecast board decisions that have a detrimental impact on governance. While it could be argued that the simple announcement of the various items to be discussed at the shareholder's meeting may be enough to incite short selling, the fact remains that no corporate decision is final until it has been submitted to a vote and therefore only becomes factual at that time. Gordon and Pound (1993) investigate how ownership structure affects voting outcome and show that approval rates for shareholder proposals vary significantly with the level of ownership by outsiders, institutions and blockholders. For example, poison-pill repeals can enjoy a relatively high level of support (55-80\%) while items pertaining to management or board directors such as disclosing compensation, minimum stock ownership, banning golden parachutes or limiting terms sometimes receive a mere $5 \%$ of the votes. There is simply no infallible method to reliably predict voting outcome simply on the basis that a proposal is made. The CGQ metric simply provides a numerical 
measure of such corporate decisions; it is not meant to be perceived as the focal point of short traders as they rather act on the expected impact of a specific corporate action.

\section{TESTS OF ROBUSTNESS}

\subsection{Asymmetric Effects of Changes in Governance}

We also expect that the effect of the change in CGQ rating will have an asymmetric influence on short sales. A positive change in CGQ rating may have a limited impact on short sales as a seller can only reduce his short position until it becomes flat. In contrast, a negative change allows for more latitude as it only limits short sales to the maximum of the float or lendable shares. The only dampener on short sales is the escalating cost of borrowing the stock. To account for this possibility, we divide $\Delta G o v R_{i, t}$ into its positive and negative components. Neg $\Delta G o v R_{i, t}$ is $\Delta G o v R_{i, t}$ multiplied by a dummy variable with a value of 1 for negative changes in governance and 0 for positive ones. Pos $\Delta G o v R_{i, t}$ has the same properties but in reverse since the dummy takes the value of 1 for positive changes in governance and 0 otherwise. We expect the coefficient of $N e g \Delta G o v R_{i, t}$ to be negative and statistically significant, and that of $\operatorname{Pos} \Delta G o v R_{i, t}$ to be positive and substantially smaller in absolute value. We modify regression model (3) as follows with the change in CGQ rating split into its two components and estimate it using the same methods as described in section 5.2:

$$
\begin{aligned}
\text { SUlization }_{i, t}=\beta_{0} & +\beta_{1} \Delta \text { logShortCost }_{i, t}+\beta_{2} \Delta \text { Utilization }_{i, t-1}+\beta_{3} \text { Pos }_{\text {Gov }} \text { Gov }_{i, t} \\
& +\beta_{4} \operatorname{Neg} \Delta \text { Gov }_{i, t}+\beta_{5} \Delta \text { InstOwn }_{i, t}+\varepsilon_{i, t}
\end{aligned}
$$

where all the terms are as previously defined.

Based on the FE regression results summarized in Panel A of Table 6, the regression is highly significant $(F$-statistic $=105, \mathrm{p}$-value $=0.000)$ although its adjusted $\mathrm{R}^{2}$ is only 0.06 . All coefficients 
are statistically significant whether they are measured against standard t-statistics or the more rigorous Bayes-adjusted critical values, with the exception of $\operatorname{Pos} \Delta G o v R_{i, t}$ which exhibits the lower significance level of $95 \%$ (t-value of 2.46). As we hypothesized, the absolute value of the coefficient $\beta_{4}$ is approximately $50 \%$ higher than that of $\beta_{3}$, signalling that negative changes in governance have a larger impact on utilization than positive ones. This implies that short sellers respond more strongly to forecasted negative corporate events than positive ones. Furthermore, the difference in sign between $\beta_{3}$ and $\beta_{4}$ indicates that their reaction is commensurate with the direction of the change in governance. Panel B reports the results of the robustness test completed using the dynamic panel estimation process. The outcome differs from the least square method in two ways; first, all coefficients are statistically significant to the Bayes-adjusted critical t-statistics. Second, although the signs match those of model (3), the ratio between positive and negative changes in governance is anomalous, with a much larger absolute value for $\operatorname{Pos} \Delta G o v R_{i, t}$ than $N e g \Delta G o v R_{i, t}(0.2098$ for the former versus 0.0461 for the latter), casting a doubt on the nature of the asymmetric relationship.

\section{[Please insert table 6 about here.]}

As a further test of robustness, we run a similar regression with the change in lagged utilization, $\Delta$ Utilization $_{i, t-1}$, as the dependent variable to test if the effect is also present when we consider the change in the level of utilization prior to the corporate event (i.e., change in governance rating). This test also verifies if the short position was in place for more than two periods, giving a possible indication as to the timeframe under consideration by short sellers. The specific regression estimated is:

$$
\begin{aligned}
& \Delta \text { Utilization }_{i, t-1}=\beta_{0}+\beta_{1} \Delta \text { log ShortCost }_{i, t-1}+\beta_{2} \Delta \text { Utilization }_{i, t-2}+\beta_{3} \text { Pos }_{\text {SGov }}, t \\
& +\beta_{4} \operatorname{Neg} \Delta G o v R_{i, t}+\beta_{5} \Delta \text { InstOwn } n_{i, t-1}+\varepsilon_{i, t}
\end{aligned}
$$


where all the terms are as previously defined.

As reported in Panel A of Table 7, the fixed-effects coefficients are all statistically significant and comparable to that for regression model (5), signifying that the asymmetric actions are present when the sellers accumulate or divest short positions prior to a change in CGQ ratings. The ratio of the absolute value of $\beta_{4}$ over $\beta_{3}$ is 1.61 , replicating our previous findings that negative governance changes have a larger impact than positive ones. For a negative (positive) change in CGQ rating, short sellers increase (decrease) their share-borrowing utilization during the two months prior to the governance rating change. More succinctly, short sellers significantly change their holdings from period t-2 to t-1 in anticipation of the change in governance, lending further credence to the third hypothesis. Panel B shows that these results are replicated with the dynamic system GMM panel estimation model with the exception that the relationship between positive changes in governance and the lagged change in utilization is not significant. In economic terms, a trader with a short stock balance faced with an optimistic governance event can only reduce his negative holdings until he reaches a flat position. Alternatively, under adverse expectations, he can continue selling as long as the supply of lendable shares holds, thus anticipated positive changes in CGQ ratings should have a less significant impact on short sales than negative ones.

\section{[Please insert table 7 about here.]}

\subsection{Excess Lagged Utilization and Expectations of a Change in Governance}

Our third hypothesis rests on the premise that short sellers may be able to foresee the next change in CGQ rating. Our results from equations (4) and (6) confirm this possibility. However, from regression model (4), the coefficient of $\Delta G o v R_{i, t}$ obtained using the least squares estimation process does not meet the more severe Bayesian-adjusted critical t-value. To further investigate this weaker result, we design a new test using excess lagged utilization as the dependent variable. 
Excess lagged utilization $\left(X_{S}\right.$ Utilization $\left._{i, t-1}\right)$ is defined as lagged utilization minus average

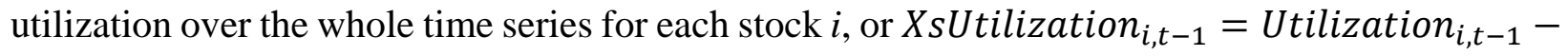
AvgUtilization $_{i}$. As a further test, we estimate the following regression model:

$$
\begin{gathered}
\text { XsUtilization }_{i, t-1}=\beta_{0}+\beta_{1} \text { logShortCost }_{i, t-1}+\beta_{2} \text { Utilization }_{i, t-2} \\
+\beta_{3} \operatorname{Pos}_{\text {Gov }} \text { Gov }_{i, t}+\beta_{4} \text { Neg } \Delta \text { Gov }_{i, t}+\beta_{5} \text { InstOwn }_{i, t-1}+\varepsilon_{i, t}
\end{gathered}
$$

where all the terms are as previously defined.

If short sellers can anticipate changes in governance, excess lagged utilization should be related to changes in the CGQ rating. As was the case for regression models (5) and (6), we separate positive and negative changes in governance to test for asymmetry. We report the results in table 8. For our sample of 37,677 observations, the fixed-effects regression is highly significant (Fstatistic $=2185 ; \mathrm{p}$-value $=0.000)$ with good explanatory power $\left(\mathrm{R}^{2}=0.22\right)$. Except for $\beta_{3}$, all the coefficients meet the higher Bayesian-adjusted critical t-value hurdle, confirming that short sellers adjust their positions in expectation of changes in governance. As per regression models (5) and (6), asymmetry is still present in the period prior to the change in CGQ rating, with a much more

pronounced reaction for negative variations (i.e., $\beta_{3}$ versus $\beta_{2}$ ). The weaker significance of $\beta_{3}$ can be explained by the fact that short sellers are more interested in negative changes in governance than positive ones. These results further substantiate our third hypothesis.

[Please insert table 8 about here.]

\section{CONCLUSION}

This paper investigates the relationship between short sales and governance. It contributes to the literature by providing a new insight on the tools used by short sellers to generate profits. We argue that short sales are linked to the overall level of corporate governance of a firm and that 
sellers react contemporaneously to changes in such governance. We investigate the determinants of relative short interest identified in the prior literature and find that the use of governance, institutional ownership and lagged utilization as independent variables renders insignificant other regressors such as fundamental ratios, market capitalization, the existence of options, etc.

Our findings support previous studies concluding that shorting costs increase with utilization and that short sellers take appropriate action when faced with contemporaneous announcements and news related to changes in corporate governance. Furthermore, our results show that short traders may also be able to forecast or manipulate changes in governance structure and react accordingly prior to the said changes. This reaction is asymmetric, with a pronounced increase in short positions for actual and expected negative shifts in governance and a more subdued repurchase of previously shorted stock for positive changes. Our findings support the notion that short sellers are informed investors. Alternatively, our results could be interpreted as evidence of the use of a legal but dubious technique called record-date capture where the seller decouples economic and voting ownership over the record date preceding a corporate event. He then sells the stock and votes against the best interest of the firm at the shareholder's meeting, thus having a negative impact on the level of governance and decreasing firm value before repurchasing the shares at a reduced price. 


\section{REFERENCES}

Aggarwal, R., P. A. C. Saffi and J. Sturgess. "The Role of Institutional Investors in Voting: Evidence from the Securities Lending Market.” Working paper. Georgetown McDonough School of Business, 2014.

Aitken, M., A. Frino, M. McCorry and P. Swan. "Short Sales Are Almost Instantaneously Bad News: Evidence from the Australian Stock Exchange.” Journal of Finance (1998): 53, 2205-2223.

Arellano, M. and O. Bover. "Another Look at the Instrumental Variable Estimation of ErrorComponents Models.” Journal of Econometrics, (1995): 68, 29-51.

Arnold, T., A. Butler, T. Crack and Y. Zhang. "The Information Content of Short Interest: A Natural Experiment.” Journal of Business, (2005): 78:4, 1307-1336.

Asquith, P. and L. Meulbroek. “An Empirical Investigation of Short Interest.” Working Paper. Harvard University, Boston, 1996.

Beber, A. and M. Pagano. "Short-selling Bans around the World: Evidence from the 2007-09 Crisis.” Journal of Finance, (2013): 68:1, 343-381.

Boehmer, E., C. Jones and X. Zhang, “Which Shorts are Informed?” Journal of Finance, (2008): 63:2, 491-527.

Boehmer, E., C. Jones and X. Zhang. "Shackling the short sellers: The 2008 Shorting Ban.” The Review of Financial Studies, (2013): 26:6, 1363-1400.

Boulton, T. and M. Braga-Alves. “The skinny on the 2008 naked short sale restrictions.” Journal of Financial Markets, (2010): 13, 397-421.

Brav, A. and R. D. Matthews. "Empty Voting and the Efficiency of Corporate Governance." Journal of Financial Economics, (2011): 99, 289-307.

Brown, L. and M. Caylor. “Corporate Governance and Firm Operating Performance.” Review of Quantitative Finance and Accounting, (2009): 32: 2, 129-144.

Charoenrook, A. and H. Daouk. "Market-wide short selling restrictions. Working Paper, Vanderbilt University and Cornell University, 2005.

Christoffersen, S. E. K., C. C. Geczy, D. K. Musto and A. V. Reed. "Vote Trading and Information Aggregation.” The Journal of Finance, (2007): 62:6, 2897-2929.

Christophe, S., M. Ferri and J. Angel. “Short-selling prior to Earnings Announcements.” Journal of Finance, (2004): 59, 1845-75.

Chung, K. H., J Elder and J.-C. Kim. “Corporate Governance and Liquidity.” Journal of Financial and Quantitative Analysis, (2010): 45, 265-291.

D’Avolio, G. “The Market for Borrowing Stock.” Journal of Financial Economics, (2002): 66. 271-306.

Daniel, K., D. Hirshleifer and A. Subrahmanyam. "Investor Psychology and Security Market Under- And Over-Reactions.” Journal of Finance, (1998): 53, 1839-85.

DeBondt, W. F. M. and R. Thaler. “Does the Stock Market Overreact?” Journal of Finance, (1985): 40, 793-805.

Dechow, P., A. Hutton, L. Meulbroek and R. Sloan. "Short-sellers, Fundamental Analysis and Stock Returns.” Journal of Financial Economics, (2001): 61, 77-106.

Desai, H., K. Ramesh, S. Thiagarajan and B. Balachandran. "An investigation of the Information Role of Short Interest in the Nasdaq Market.” Journal of Finance, (2002): 52, 2263-87. 
Desai, H., S. Krishnamurthy and K. Venkataraman. "Do Short Sellers Target Firms with Poor Earnings Quality? Evidence from Earnings Restatements.” Review of Accounting Studies, (2006): 11, 71-90.

Diamond, D. W. and R. E. Verracchia. "Constraints on Short-Selling and Asset Price Adjustment to Private Information.” Journal of Financial Economics, (1987): 18, 277-311.

Diether, K.B., K-H Lee and I.M. Werner. "Short Sales Strategies and Return Predictability.” The Review of Financial Studies, (2008): 22:2, 575-607

Drobetz, W., A. Schillhofer and H. Zimmermann. "Corporate Governance and Expected Stock Return: Evidence from Germany.” Journal of European Financial Management, (2004): $10: 2,267-293$

Edwards, E.O. and P.W. Bell. “The Theory of Measurement of Business Income. University of California Press, Berkeley, 1961.

Engelberg, J., A.V. Reed and M. Ringgenberg. "How are Shorts Informed? Short Sellers, News, and Information Processing.” Journal of Financial Economics, (2012): 105:2, 260-278.

Fox, M.B., L.R. Glosten and P.C. Tetloc. "Short Selling and the News: A Preliminary Report on an Empirical Study.” New York Law School Law Review, (2010): 54, 645-686.

Francis, J., M. Venkatachalam and Y. Zhan. "Do Short Sellers Convey Information about Changes in Fundamentals Or Risk?” Working paper, Duke University, 2005.

Gintschel, A. Short interest on NASDAQ. Working paper, Emory University, 2001.

Gompers, P., J. Ishii and A. Metrick. “Corporate Governance and Equity Prices.” Quarterly Journal of Economics, (2001): 116, 107-155.

Gordon, L. A. and J. Pound. "Information, Ownership Structure and Shareholder Voting: Evidence from Shareholder-Sponsored Corporate Governance Proposals.” Journal of Finance, (1993): 48, 697-718.

Graham, J. E., J.C. Hughen and C.G. McDonald. "The Determinants of Short Sales Activity.” Working paper. University of Missouri-Columbia, 1999.

Hong, H. and J. Stein. "A Unified Theory of Underreaction, Momentum Trading and Overreaction in Asset Markets.” Journal of Finance, (1999): 54, $2143-84$.

Hu, H. T. C. and B. Black. “The New Vote Buying: Empty Voting and Hidden (Morphable) Ownership.” Southern California Law Review, (2006): 79:4, 811-908.

Jones, C. and O. Lamont. "Short Sales Constraints and Stock Returns.” Journal of Financial Economics, (2002): 66, 207-39.

Karpoff, J.M. and X. Lou. "Short Sellers and Financial Misconduct.” Journal of Finance, (2010): 65:5, 1879-1913.

Leamer, E. E. “Specification searches: Ad Hoc Inference with Non-experimental Data.” John Wiley and Sons, New York, 1978.

Lindley, D. V. “A statistical paradox.” Biometrika, (1957): 44, 187-192.

McKenzie, M. and Ó.T. Henry. “The determinants of Short Selling in the Hong Kong Equities Market.” University of Melbourne Economics Department, 2007.

Miller. E.M. “Risk, Uncertainty and Divergence of Opinion.” Journal of Finance, (1977): 32, 1151-68.

Moore, S. and G. E. Porter. "An Examination of the Relationship between Corporate Governance Regime and Corporate Performance.” Working Paper, Boler School of Business, 2007.

Ohlson, J. "Earnings, Book Values, and Dividends in Security Valuation.” Contemporary Accounting Research (1995): 11, 661-687. 
Reed, A. “Costly short-selling and Stock Price Adjustment to Earnings Announcements.” Working Paper, University of North Carolina, 2007.

Ringe, W.G. "Empty voting revisited: The Telus Saga.” Journal of International Banking and Financial Law, (2013): forthcoming.

Saffi, P.A. and K. Sigurdsson. "Price Efficiency and Short Selling.” Review of Financial Studies, (2011): 24:3, 821-852.

Scheinkman, J. and W. Xiong. “Overconfidence and Speculative Bubbles.” Journal of Political Economy, (2003): 111, 1183-1219.

Senchack, A.J. and L.T. Starks. "Short-sale Restrictions and Market Reaction to Short-Interest Announcements.” Journal of Financial and Quantitative Analysis, (1993): 28, 177-194.

Sias, R.W. and L.T. Starks. "Institutions and Individuals at the Turn-Of-The-Year.” Journal of Finance, (1997): 52, 1543-1562.

Woolridge, J.R. and A. Dickinson. "Short Selling and Common Stock Prices.” Financial Analysts Journal, (1994): 50, 30-38. 
Table 1. Descriptive statistics for the sample

This table provides basic statistics for our sample. The original dataset contains 146,594 monthly observations including 3962 firms. It was reduced to 113,664 monthly observations for 3072 firms after removing illiquid stocks, penny stocks and delistings, and then further reduced to 67,321 monthly observations for 3072 firms after the removal of missing data and utilization levels lower than the $2.5 \%$ threshold. The period under study covers a full market cycle from July 2006 to July 2009. Gov $R_{i, t}$ is the CGQ rating for stock $i$ for month $t$; Utilization $_{i, t}$ is the average ratio of shares borrowed to lendable shares for stock $i$ during month $t$; logShortCost i,t $_{\text {S }}$ is the log of the value-weighted average shorting fee for stock $i$ and month $t$; and InstOwn $_{i, t}$ is the percentage of the free float of stock $i$ owned by institutional entities for month $t$.

\begin{tabular}{|l|c|c|c|c|c|c|}
\hline \multicolumn{1}{|c|}{ Variable } & Range & Mean & Median & Std. Deviation & Skewness & Kurtosis \\
\hline GovR $_{i, t}$ & $0.1-100$ & 52.22 & 53.10 & 28.42 & -0.09 & 1.83 \\
\hline Utilization $_{i, t}$ & $2.5-100$ & 29.83 & 23.23 & 22.91 & 0.94 & 3.03 \\
\hline logShortCost $_{i, t}$ & $0-9.44$ & 3.57 & 2.92 & 1.50 & 0.70 & 2.91 \\
\hline InstOwn $_{i, t}$ & $0-0.98$ & 0.69 & 0.74 & 0.30 & -0.38 & 2.70 \\
\hline
\end{tabular}

\begin{tabular}{|l|c|c|c|c|}
\hline Correlation & GovR $_{i, t}$ & Utilization $_{i, t}$ & logShortCost $_{i, t}$ & InstOwn $_{i, t}$ \\
\hline GovR $_{i, t}$ & 1.00 & -0.06 & -0.02 & 0.07 \\
\hline Utilization $_{i, t}$ & -0.06 & 1.00 & 0.52 & 0.001 \\
\hline logShortCost $_{i, t}$ & -0.02 & 0.52 & 1.00 & -0.27 \\
\hline InstOwn $_{i, t}$ & 0.07 & 0.001 & -0.27 & 1.00 \\
\hline
\end{tabular}


Table 2. Summary regression results for tests of the first hypothesis

This table reports summary regression results for a test of the first alternative hypothesis; namely, that a lower level of governance is associated with a higher level of short sales. Specifically, we estimate:

$$
\begin{gathered}
\text { Utilization }_{i, t}=\beta_{0}+\beta_{1} \text { Gov }_{i, t}+\beta_{2} \operatorname{logShortCost}_{i, t}+\beta_{3} \text { Utilization }_{i, t-1} \\
+\beta_{4} \text { InstOwn }_{i, t}+\varepsilon_{i, t}
\end{gathered}
$$

Utilization $_{i, t}$ is the average ratio of shares borrowed to shares lendable for stock $i$ during month $t$; Gov $R_{i, t}$ is the CGQ rating for stock $i$ for month $t$; $\operatorname{logShortCost}_{i, t}$ is the log of the valueweighted average shorting fee for stock $i$ for month $t$; Utilization $n_{i, t-1}$ is the independent variable lagged one month to control for short momentum; and InstOwn $n_{i, t}$ is the percentage of shares owned by institutional investors of stock $i$ for month $t$. The sample contains 42,915 observations. The Bayes-adjusted critical t-value is \pm 3.27 . Panel A reports the results of the hypothesis tested by using a panel regression model with period fixed effects and White diagonal standard errors to account for clustering. Panel B reports the regression output for equation (2)

\begin{tabular}{|c|c|c|c|c|}
\hline \multicolumn{5}{|c|}{ Panel A - Estimation Method with Period Fixed Effects } \\
\hline Variable & Coefficient & Std. Error & t-statistic & p-value \\
\hline C & -2.7254 & 0.2025 & -13.45 & 0.0000 \\
\hline GovR $_{i, t}$ & -0.0096 & 0.0015 & -6.27 & 0.0000 \\
\hline $\operatorname{logShortCost}_{i, t}$ & 1.4427 & 0.0479 & 30.09 & 0.0000 \\
\hline Utilization $_{i, t-1}$ & 0.8661 & 0.0030 & 289.04 & 0.0000 \\
\hline InstO $_{w} n_{i, t}$ & 2.7412 & 0.1727 & 15.87 & 0.0000 \\
\hline \multicolumn{2}{|l|}{ Adj. R-square } & 0.85 & & \\
\hline \multicolumn{2}{|l|}{ F-statistic } & 9633 & & \\
\hline \multicolumn{2}{|l|}{ Prob(F-statistic) } & 0.0000 & & \\
\hline \multicolumn{2}{|l|}{ Durbin-Watson statistic } & 2.02 & & \\
\hline
\end{tabular}
estimated using a dynamic system GMM panel model.

\begin{tabular}{|l|r|r|r|r|}
\hline Panel B - Dynamic System GMM Panel Model \\
\hline Variable & Coefficient & Std. Error & t-statistic & p-value \\
\hline Gov $_{i, t}$ & -0.1791 & 0.0242 & -7.39 & 0.0000 \\
\hline logShortCost $_{i, t}$ & 0.7837 & 0.1127 & 6.95 & 0.0000 \\
\hline Utilization $_{i, t-1}$ & 0.5750 & 0.0147 & 38.88 & 0.0000 \\
\hline Utilization $_{i, t-2}$ & -0.0319 & 0.0064 & -4.95 & 0.0000 \\
\hline InstOwn $_{i, t}$ & 74.403 & 3.5197 & 21.13 & 0.0000 \\
\hline J-statistic & & 562 & \multicolumn{3}{l}{} \\
\cline { 1 - 3 } & & \multicolumn{3}{l}{}
\end{tabular}


Table 3. Summary regression results for a test of the second hypothesis

This table contains the summary regression results for a test of $H_{a}^{2}$; namely, that a negative (positive) change in the governance level of a firm is positively (negatively) related contemporaneously with the change in the level of short sales. Since institutional ownership is obtained quarterly and all other variables have a monthly frequency, the sample is reduced to exclude all observations where $\Delta I n s t O w n_{i, t}$ is equal to 0 (i.e., between reporting months). This situation occurs for two of the months per quarter. The final sample contains 12,199 observations. Our second alternate hypothesis is estimated using a panel regression method with period fixed effects and White diagonal standard errors to account for clustering (Panel A) and a dynamic system GMM panel model for robustness purposes (Panel B). Specifically, we estimate:

$$
\begin{gathered}
\text { SUtilization }_{i, t}=\beta_{0}+\beta_{1} \Delta \text { Gov }_{i, t}+\beta_{2} \text { LlogShortCost }_{i, t}+\beta_{3} \text { SUtilization }_{i, t-1} \\
+\beta_{4} \Delta \text { InstOwn }_{i, t}+\varepsilon_{i, t}
\end{gathered}
$$

$\Delta$ Utilization $_{i, t}$ is the change in the average ratio of shares borrowed to shares lendable for stock $i$ from month $t-1$ to month $t ; \Delta G o v R_{i, t}$ is the change in the CGQ rating for stock $i$ from month $t-1$ to month $t$; $\Delta$ logShortCost ${ }_{i, t}$ is the log of the change in the value-weighted average shorting fee for stock $i$ from month $t-1$ to month $t$; $\Delta$ Utilization $_{i, t-1}$ is the change in the lagged independent variable from month $t-2$ to month $t-1$ to control for lagged short momentum; and $\Delta$ InstOwn $_{i, t}$ is the change in the percentage of shares owned by institutional investors of stock $i$ from $t-1$ to

\begin{tabular}{|c|c|c|c|c|}
\hline \multicolumn{5}{|c|}{ Panel A - Estimation Method with Period Fixed Effects } \\
\hline Variable & Coefficient & Std. Error & t-statistic & p-value \\
\hline C & -0.0456 & 0.0809 & -0.56 & 0.5727 \\
\hline$\Delta G o v R_{i, t}$ & -0.0564 & 0.0107 & -5.25 & 0.0000 \\
\hline$\Delta \operatorname{logShortCost}_{i, t}$ & 0.8051 & 0.0815 & 9.87 & 0.0000 \\
\hline Utilization $_{i, t-1}$ & -0.0916 & 0.0149 & -6.11 & 0.0000 \\
\hline$\Delta$ InstOwn & 12.5911 & 1.8629 & 6.76 & 0.0000 \\
\hline \multicolumn{2}{|l|}{ Adj. R-square } & 0.08 & & \\
\hline \multicolumn{2}{|l|}{ F-statistic } & 65 & & \\
\hline \multicolumn{2}{|l|}{ Prob(F-statistic) } & 0.0000 & & \\
\hline \multicolumn{2}{|l|}{ Durbin-Watson statistic } & 1.88 & & \\
\hline
\end{tabular}
month $t$. The Bayes-adjusted critical t-value is \pm 3.07 .

\begin{tabular}{|l|r|r|r|r|}
\hline \multicolumn{5}{|l|}{ Panel B - Dynamic System GMM Panel Model } \\
\hline Variable & Coefficient & Std. Error & t-statistic & p-value \\
\hline$\Delta$ Gov $_{i, t}$ & -0.1834 & 0.0071 & -25.77 & 0.0000 \\
\hline$\Delta$ logShortCost $_{i, t}$ & -0.0279 & 0.0102 & -2.72 & 0.0064 \\
\hline$\Delta$ Utilization $_{i, t-1}$ & -0.0518 & 0.0034 & -14.99 & 0.0000 \\
\hline$\Delta$ Utilization $_{i, t-2}$ & 2.4928 & 0.0571 & 43.59 & 0.0000 \\
\hline
\end{tabular}




\begin{tabular}{|l|r|r|r|r|}
\hline \multicolumn{1}{|l|}{ InstOwn $_{i, t}$} & 53.678 & 0.5770 & 93.02 & 0.0000 \\
\cline { 1 - 3 } J-statistic & & 298 & \multicolumn{2}{l}{} \\
\cline { 1 - 2 }
\end{tabular}


Table 4. Summary regression results for a test of the second hypothesis using the reduced sample $(\Delta G o v R=0)$

This table contains the results for a test of $H_{a}^{2}$ when $\Delta G o v R=0$ in order to test if there is a significant change in lagged utilization when the change in CGQ rating is zero. This hypothesis is estimated with a reduced sample of 1,117 pooled observations, using a panel regression model with period fixed effects and White diagonal standard errors to account for clustering (Panel A) and a dynamic system GMM panel model for robustness purposes (Panel B). The estimated equation is:

$$
\begin{gathered}
\text { Utilization }_{i, t}=\beta_{0}+\beta_{1} \Delta \text { logShortCost }_{i, t}+\beta_{2} \text { SUtilization }_{i, t-1} \\
+\beta_{3} \Delta \text { InstOwn }_{i, t}+\varepsilon_{i, t}
\end{gathered}
$$

$\Delta$ Utilization $_{i, t}$ is the change in the average ratio of shares borrowed to shares lendable for stock $i$ from month $t$ - 1 to month $t$; $\Delta$ logShortCost $_{i, t}$ is the change in the log of the value-weighted average shorting fee for stock $i$ from month $t-1$ to month $t$; Utilization $_{i, t-1}$ is the change in the lagged independent variable from month $t-2$ to month $t-1$ to control for lagged short momentum; and $\Delta$ InstO $w n_{i, t}$ is the change in the percentage of shares owned by institutional investors of stock

\begin{tabular}{|c|c|c|c|c|}
\hline \multicolumn{5}{|c|}{ Panel A - Estimation Method with Period Fixed Effects } \\
\hline Variable & Coefficient & Std. Error & t-statistic & p-value \\
\hline$C$ & 0.0174 & 0.2701 & 0.06 & 0.9485 \\
\hline$\Delta \log$ ShortCost $_{i, t}$ & 0.7307 & 0.2322 & 3.14 & 0.0017 \\
\hline Utilization $_{i, t-1}$ & 0.0060 & 0.0382 & 0.16 & 0.8745 \\
\hline$\Delta I n s t O w n_{i, t}$ & 17.069 & 5.8226 & 2.93 & 0.0034 \\
\hline \multicolumn{2}{|l|}{ Adj. R-square } & 0.09 & & \\
\hline \multicolumn{2}{|l|}{ F-statistic } & 7.77 & & \\
\hline \multicolumn{2}{|l|}{ Prob(F-statistic) } & 0.0000 & & \\
\hline \multicolumn{2}{|l|}{ Durbin-Watson statistic } & 1.94 & & \\
\hline
\end{tabular}
$i$ from $t-1$ to month $t$. The Bayes-adjusted critical t-value is \pm 2.65 .

\begin{tabular}{|c|c|c|c|c|}
\hline \multicolumn{5}{|c|}{ Panel B - Dynamic System GMM Panel Model } \\
\hline Variable & Coefficient & Std. Error & t-statistic & p-value \\
\hline$\Delta \log$ ShortCost $_{i, t}$ & 1.2771 & 0.1107 & 11.53 & 0.0000 \\
\hline$\Delta$ Utilization $_{i, t-1}$ & -0.0237 & 0.0171 & -1.384 & 0.1664 \\
\hline$\Delta$ Utilization $_{i, t-2}$ & -0.1831 & 0.0146 & -12.46 & 0.0000 \\
\hline$\Delta$ InstOwn $_{i, t}$ & 43.278 & 1.3053 & 33.15 & 0.0000 \\
\hline \multicolumn{2}{|l|}{ J-statistic } & 160 & & \\
\hline
\end{tabular}


Table 5. Summary regression results for a test of the third hypothesis

This table reports the summary regression results for a test of our third alternative hypothesis that short sellers can anticipate changes in governance so that they take the proper position prior to the change in the governance rating. A change in the governance level of a firm is thus negatively related to the preceding level of short interest. Panel A reports the results of the hypothesis tested by using a panel regression model with period fixed effects and White diagonal standard errors to account for clustering. Panel B reports the regression output for equation (4) estimated using a dynamic system GMM panel model. The regression model estimated is:

$$
\begin{gathered}
\text { Utilization }_{i, t-1}=\beta_{0}+\beta_{1} \Delta \text { Gov }_{i, t}+\beta_{2} \text { logShortCost }_{i, t-1}+\beta_{3} \text { Utilization }_{i, t-2} \\
+\beta_{4} \text { InstOwn }_{i, t-1}+\varepsilon_{i, t}
\end{gathered}
$$

Utilization $_{i, t-1}$ is the average ratio of shares borrowed to shares lendable for stock $i$ for month $t-1 ; \Delta G o v R_{i, t}$ is the change in the CGQ rating for stock $i$ from month $t-1$ to $t$; $\operatorname{logShortCost}_{i, t-1}$ is the change in the log of the value-weighted average shorting fee for stock $i$ from month $t-2$ to month $t-1$; Utilization $n_{i, t-2}$ is the independent variable used to control for lagged short momentum; and InstO $w n_{i, t-1}$ is the percentage of shares owned by institutional investors of stock $i$ for month $t-1$. The sample is composed of 38,776 observations. The Bayes-adjusted

\begin{tabular}{|c|c|c|c|c|}
\hline \multicolumn{5}{|c|}{ Panel A - Estimation Method with Period Fixed Effects } \\
\hline Variable & Coefficient & Std. Error & t-statistic & p-value \\
\hline C & -3.1505 & 0.1852 & -17.01 & 0.0000 \\
\hline$\Delta G o v R_{i, t}$ & -0.0080 & 0.0042 & -1.89 & 0.0588 \\
\hline $\operatorname{logShortCost}_{i, t-1}$ & 1.4461 & 0.0444 & 32.51 & 0.0000 \\
\hline Utilization $_{i, t-2}$ & 0.8637 & 0.0030 & 277.37 & 0.0000 \\
\hline InstOWn $_{i, t-1}$ & 2.9603 & 0.1777 & 16.66 & 0.0000 \\
\hline \multicolumn{2}{|l|}{ Adj. R-square } & 0.84 & & \\
\hline \multicolumn{2}{|l|}{ F-statistic } & 52,608 & & \\
\hline \multicolumn{2}{|l|}{ Prob(F-statistic) } & 0.0000 & & \\
\hline \multicolumn{2}{|l|}{ Durbin-Watson statistic } & 2.02 & & \\
\hline
\end{tabular}
critical t-value is \pm 3.25 .

\begin{tabular}{|l|r|r|r|r|}
\hline \multicolumn{5}{|l|}{ Panel B - Dynamic System GMM Panel Model } \\
\hline Variable & Coefficient & Std. Error & t-statistic & p-value \\
\hline$\Delta$ Gov $_{i, t}$ & -0.0495 & 0.0142 & -3.46 & 0.0005 \\
\hline logShortCost $_{i, t-1}$ & 0.5495 & 0.1286 & 4.27 & 0.0000 \\
\hline Utilization $_{i, t-2}$ & 0.5611 & 0.0154 & 36.2 & 0.0000 \\
\hline Utilization $_{i, t-3}$ & -0.0287 & 0.0067 & -4.26 & 0.0000 \\
\hline InstOWn $_{i, t-1}$ & 68.918 & 3.4795 & 19.80 & 0.0000 \\
\hline J-statistic & & 515 & \multicolumn{2}{l}{} \\
\cline { 1 - 3 } & &
\end{tabular}




\section{Table 6. Summary regression results for asymmetry in short-seller reactions to governance changes}

This table reports the summary regression results for a test of the presence of asymmetry in the reactions of short sellers to changes in governance. Panel A reports the results of the hypothesis tested by using a panel regression model with period fixed effects and White diagonal standard errors. As a test of robustness, Panel B provides the regression output for equation (5) estimated using a dynamic system GMM panel model. The sample contains 38,746 observations. The regression estimated is:

$$
\begin{aligned}
& \Delta \text { Utilization }_{i, t}=\beta_{0}+\beta_{1} \Delta \text { logShortCost }_{i, t}+\beta_{2} \Delta \text { Utilization }_{i, t-1}+\beta_{3} \text { Pos }_{\text {Gov }} R_{i, t} \\
& +\beta_{4} \text { Neg } \Delta \operatorname{Gov}_{i, t}+\beta_{5} \Delta \operatorname{InstOwn_{i,t}}+\varepsilon_{i, t}
\end{aligned}
$$

$\Delta$ Utilization $_{i, t}$ is the change in the average ratio of shares borrowed to shares lendable for stock $i$ from month $t-1$ to month $t ; \Delta \log$ ShortCost $_{i, t}$ is the log of the change in the value-weighted average shorting fee for stock $i$ from month $t-1$ to month $t$; $\Delta$ Utilization $_{i, t-1}$ is the change in the lagged independent variable from month $t-2$ to month $t-1$ to control for lagged short momentum; $\operatorname{Pos} \Delta G o v R_{i, t}$ is the change in the CGQ rating for stock $i$ from month $t-1$ to $t$ multiplied by a dummy variable that is equal to 1 if the change is positive and zero otherwise; Neg $\Delta G o v R_{i, t}$ is the change in the CGQ rating for stock $i$ from month $t-1$ to $t$ multiplied by a dummy variable that is equal to 1 if the change is negative and zero otherwise; and $\Delta \operatorname{InstO}_{w} n_{i, t}$ is the change in the percentage of shares owned by institutional investors of stock $i$ from $t-1$ to month $t$. The Bayes-

\begin{tabular}{|c|c|c|c|c|}
\hline \multicolumn{5}{|c|}{ Panel A - Estimation Method with Period Fixed Effects } \\
\hline Variable & Coefficient & Std. Error & t-statistic & p-value \\
\hline C & -0.4012 & 0.0527 & -7.60 & 0.0000 \\
\hline$\Delta \log$ ShortCost $_{i, t}$ & 0.8606 & 0.0475 & 18.11 & 0.0000 \\
\hline$\Delta$ Utilization $_{i, t-1}$ & -0.0802 & 0.0095 & -8.36 & 0.0000 \\
\hline Pos $\Delta G o v R_{i, t}$ & 0.0197 & 0.0080 & 2.46 & 0.0137 \\
\hline$N e g \Delta G o v R_{i, t}$ & -0.0301 & 0.0091 & -3.28 & 0.0010 \\
\hline$\Delta I n s t O w n_{i, t}$ & 11.890 & 1.7556 & 6.77 & 0.0000 \\
\hline \multicolumn{2}{|l|}{ Adj. R-square } & 0.06 & & \\
\hline \multicolumn{2}{|l|}{ F-statistic } & 105 & & \\
\hline \multicolumn{2}{|l|}{ Prob(F-statistic) } & 0.0000 & & \\
\hline \multicolumn{2}{|l|}{ Durbin-Watson statistic } & 1.98 & & \\
\hline
\end{tabular}
adjusted critical t-value is \pm 3.25 .

\begin{tabular}{|l|r|r|r|r|}
\hline \multicolumn{5}{|l|}{ Panel B - Dynamic System GMM Panel Model } \\
\hline Variable & Coefficient & Std. Error & t-statistic & p-value \\
\hline$\Delta$ logShortCost $_{i, t}$ & 0.9421 & 0.1279 & 7.36 & 0.0000 \\
\hline$\Delta$ Utilization $_{i, t-1}$ & -0.0381 & 0.0078 & -4.88 & 0.0000 \\
\hline Utilization $_{i, t-2}$ & -0.0433 & 0.0059 & -7.33 & 0.0000 \\
\hline
\end{tabular}




\begin{tabular}{|c|c|c|c|c|}
\hline $\operatorname{Pos} \Delta G o v R_{i, t}$ & 0.2098 & 0.0413 & 5.07 & 0.0000 \\
\hline$N e g \Delta G o v R_{i, t}$ & -0.0461 & 0.0103 & -3.52 & 0.0004 \\
\hline$\Delta I n s t O w n_{i, t}$ & 43.805 & 10.011 & 4.37 & 0.0000 \\
\hline J-statistic & & 443 & & \\
\hline
\end{tabular}


Table 7. Summary regression results for asymmetry when positions of short-sellers anticipate governance changes

This table presents summary regression results for a test if asymmetry is also present when short sellers change their short positions from month t- 2 to $\mathrm{t}-1$ in anticipation of a change in firm governance. The estimated regression is similar to regression model (5) but substitutes the change in lagged utilization as the dependent variable along with the corresponding independent variables. The regression model that is estimated is:

$$
\begin{aligned}
& \Delta \text { Utilization }_{i, t-1}=\beta_{0}+\beta_{1} \Delta \text { logShortCost }_{i, t-1}+\beta_{2} \Delta \text { Utilization }_{i, t-2}+\beta_{3} \text { Pos }_{\text {SGov }} \text { Si,t } \\
& +\beta_{4} \operatorname{Neg} \Delta G o v R_{i, t}+\beta_{5} \Delta \operatorname{InstO} w n_{i, t-1}+\varepsilon_{i, t}
\end{aligned}
$$

$\Delta$ Utilization $_{i, t-1}$ is the change in the average ratio of shares borrowed to shares lendable for stock $i$ from month $t-2$ to month $t-1$; $\Delta \log$ ShortCost $_{i, t-1}$ is the log of the change in the valueweighted average shorting fee for stock $i$ from month $t-2$ to month $t-1$; $\Delta$ Utilization $_{i, t-2}$ is the change in the lagged independent variable from month $t-3$ to month $t-2$ to control for lagged short momentum; Pos $\Delta$ Gov $R_{i, t}$ is the change in the CGQ rating for stock $i$ from month $t-1$ to $t$ multiplied by a dummy variable that is equal to 1 if the change is positive and zero otherwise; $N e g \Delta \operatorname{Gov} R_{i, t}$ is the change in the CGQ rating for stock $i$ from month $t-1$ to $t$ multiplied by a dummy variable that is equal to 1 if the change is negative and zero otherwise; and $\Delta$ InstOwn $n_{i, t-1}$ is the change in the percentage of shares owned by institutional investors of stock $i$ from $t-2$ to month $t-1$. The number of observations is 35,223. The Bayes-adjusted critical tvalue is \pm 3.24 . The results generated by using a panel regression model with period fixed effects and White diagonal standard errors are displayed in Panel A while those obtained with a

\begin{tabular}{|c|c|c|c|c|}
\hline \multicolumn{5}{|c|}{ Panel A - Estimation Method with Period Fixed Effects } \\
\hline Variable & Coefficient & Std. Error & t-statistic & p-value \\
\hline$C$ & -0.4239 & 0.0251 & -16.85 & 0.0000 \\
\hline$\Delta \log$ ShortCost ${ }_{i, t-1}$ & -0.8880 & 0.0474 & -18.72 & 0.0000 \\
\hline$\Delta$ Utilization $_{i, t-2}$ & 0.0880 & 0.0101 & 8.63 & 0.0000 \\
\hline Pos $\Delta G o v R_{i, t}$ & 0.0331 & 0.0065 & 5.01 & 0.0000 \\
\hline$N e g \Delta G o v R_{i, t}$ & -0.0533 & 0.0080 & -6.65 & 0.0000 \\
\hline$\Delta$ InstOwn $n_{i, t-1}$ & 15.893 & 1.4902 & 10.66 & 0.0000 \\
\hline \multicolumn{2}{|l|}{ Adj. R-square } & 0.03 & & \\
\hline \multicolumn{2}{|l|}{ F-statistic } & 104 & & \\
\hline \multicolumn{2}{|l|}{ Prob(F-statistic) } & 0.0000 & & \\
\hline \multicolumn{2}{|l|}{ Durbin-Watson statistic } & 2.05 & & \\
\hline
\end{tabular}
dynamic system GMM panel model (for robustness purposes) are shown in Panel B.

\begin{tabular}{|l|r|r|r|r|}
\hline \multicolumn{5}{|l|}{ Panel B - Dynamic System GMM Panel Model } \\
\hline Variable & Coefficient & Std. Error & t-statistic & p-value \\
\hline logShortCost $_{i, t-1}$ & 1.0308 & 0.0931 & 11.06 & 0.0000 \\
\hline Utilization $_{i, t-2}$ & -0.0466 & 0.0077 & -6.01 & 0.0000 \\
\hline
\end{tabular}




\begin{tabular}{|c|c|c|c|c|}
\hline$\Delta$ Utilization $_{i, t-3}$ & -0.0325 & 0.0062 & -5.16 & 0.0000 \\
\hline $\operatorname{Pos} \Delta G o v R_{i, t}$ & -0.0073 & 0.0171 & -0.42 & 0.6681 \\
\hline$N e g \Delta G o v R_{i, t}$ & -0.1768 & 0.0234 & -7.53 & 0.0000 \\
\hline$\Delta \operatorname{InstOwn_{i,t-1}}$ & 31.649 & 3.3799 & 9.36 & 0.0000 \\
\hline J-statistic & & 615 & & \\
\hline
\end{tabular}


Table 8. Summary regression results for a robustness test of whether the positions of short-sellers change prior to governance changes

This table reports the summary results for a test of robustness for the third hypothesis that short sellers adopt a position in expectation of changes in governance. A sample of 37,677 events is used to test if the lagged excess in short-sale utilization is related to contemporaneous positive and negative changes in CGQ rating. The following regression model is estimated using a panel regression with period fixed-effects and White diagonal standard errors:

$$
\begin{gathered}
\text { XsUtilization }_{i, t-1}=\beta_{0}+\beta_{1} \text { logShortCost }_{i, t-1}+\beta_{2} \text { Utilization }_{i, t-2} \\
+\beta_{3} \operatorname{Pos}_{\text {Gov }} \text { Gov }_{i, t}+\beta_{4} \operatorname{Neg} \Delta \text { Gov }_{i, t}+\beta_{5} \text { InstOwn }_{i, t-1}+\varepsilon_{i, t}
\end{gathered}
$$

$X_{s}$ tilization $_{i, t-1}$ is the excess utilization for stock $i$ for month $t-1$; $\operatorname{logShortCost~}_{i, t-1}$ is the log of the value-weighted average shorting fee for stock $i$ for month $t-1$; Utilization $_{i, t-2}$ is the average ratio of shares borrowed to shares lendable for stock $i$ for month $t-2$; Pos $\Delta G o v R_{i, t}$ is the change in the CGQ rating for stock $i$ from month $t-1$ to $t$ multiplied by a dummy variable that is equal to 1 if the change is positive and zero otherwise; $N e g \Delta G o v R_{i, t}$ is the change in the CGQ rating for stock $i$ from month $t-1$ to $t$ multiplied by a dummy variable that is equal to 1 if the change in negative and zero otherwise; and InstOwn $n_{i, t-1}$ is the percentage of the free float of stock $i$ owned by institutional entities during month $t-1$. The Bayes-adjusted critical t-value is

\begin{tabular}{|c|c|c|c|c|}
\hline Variable & Coefficient & Std. Error & t-statistic & p-value \\
\hline$C$ & -10.1374 & 0.2603 & -38.93 & 0.0000 \\
\hline $\operatorname{logShortCost}_{i, t-1}$ & 0.6936 & 0.0551 & 12.58 & 0.0000 \\
\hline Utilization $_{i, t-2}$ & 0.2529 & 0.0035 & 71.07 & 0.0000 \\
\hline $\operatorname{Pos} \Delta G o v R_{i, t}$ & 0.0207 & 0.0079 & 2.60 & 0.0091 \\
\hline$N e g \Delta G o v R_{i, t}$ & -0.0349 & 0.0081 & -4.30 & 0.0000 \\
\hline InstOwn $_{i, t-1}$ & 2.6614 & 0.2385 & 11.15 & 0.0000 \\
\hline \multicolumn{2}{|l|}{ Adj. R-square } & 0.22 & & \\
\hline \multicolumn{2}{|l|}{ F-statistic } & 2242 & & \\
\hline \multicolumn{2}{|l|}{ Prob(F-statistic) } & 0.0000 & & \\
\hline \multicolumn{2}{|l|}{ Durbin-Watson statistic } & 1.87 & & \\
\hline
\end{tabular}
\pm 3.25 . 


\section{Acknowledgements}

The authors thank Gregory Lypny, Komlan T. Sedzro, Jim Mahar (Discussant), Loic Belze (Discussant) and Emily J. Huang (Discussant) as well as participants at the meetings of the Financial Management Association (2013 Chicago), World Finance Conference (2013 Cyprus), Mid-West Finance Association (2013 Chicago) and at University of Sherbrooke for helpful comments and suggestions. Financial support from the Senior Concordia University Research Chair in Finance, IFM2 and SSHRC (Social Sciences and Humanities Research Council of Canada) are gratefully acknowledged. The usual disclaimer applies. 